ORIGINAL RESEARCH

\title{
Pulley Ruptures in Rock Climbers: Outcome of Conservative Treatment With the Pulley-Protection Splint-A Series of 47 Cases
}

\author{
Micha Schneeberger, BS; Andreas Schweizer, MD \\ From the Department of Orthopedics, Balgrist University Hospital, Zurich, Switzerland.
}

\begin{abstract}
Objective.-To evaluate the effectiveness of conservative treatment of finger flexor tendon pulley rupture with a pulley-protection splint (PPS) with regard to reduction in tendon-phalanx distance (TPD) and functional and sport-specific outcomes in a retrospective case series.

Methods.-Tendon-phalanx distance in active forced flexion was measured before and after treatment in ultrasound records. Functional and sport-specific outcomes were evaluated by means of a questionnaire, which also contained instructions for self-measurement of finger range of motion and finger strength.

Results.-Forty-seven complete pulley ruptures in 45 rock climbers (mean age, 33.4 years; range, 21.8-56.2 years) were included in the study. In the 39 patients who had follow-up ultrasound examination, PPS treatment decreased mean \pm SD TPD from $4.4 \pm 1.0 \mathrm{~mm}$ to $2.3 \pm 0.6 \mathrm{~mm}$ after A2 pulley rupture and from $2.9 \pm 0.7 \mathrm{~mm}$ to $2.1 \pm 0.5 \mathrm{~mm}$ after A4 pulley rupture. Tendon-phalanx distance was reduced in all patients. Finger range of motion $(n=42)$ and finger strength $(n=22)$ did not differ significantly between treated and contralateral sides. Of the 43 climbers who completed questionnaires, 38 had regained their previous climbing level a mean 8.8 months after pulley rupture; 1 reported reduced finger dexterity; 39 assessed their treatment results to be good, and 4 to be very good.

Conclusions.- The PPS is an effective conservative treatment modality for pulley ruptures, which reduces TPD and enables the patient to regain previous finger function.
\end{abstract}

Key words: bowstringing, finger injury, flexor tendon, pulley rupture, rock climbing

\section{Introduction}

Pulleys arch over the flexor tendon sheath, keeping the tendons close to the skeletal structures and allowing functionally optimal finger flexion (Figure 1). The most important pulleys with regard to function are the A2 and A4. ${ }^{1-3}$ Pulley ruptures are among the most frequent injuries in sport climbing. ${ }^{4,5}$ Vice versa, sport climbing accounts for the bulk of pulley ruptures; however, they also occur in nonclimbing activities, such as lifting or carrying heavy objects. ${ }^{6,7}$ The injury mechanisms seem to be uniform ${ }^{7}$ : Heavy loads on the pulley system occur when tendon deflection at the edge of the pulley is large, as is the case with the crimp grip (proximal

Presented in part at the 2nd International Rock Climbing Research Congress in Pontresina, Switzerland, September 15-19, 2014, organized by the International Rock Climbing Research Association.

Corresponding author: Micha Schneeberger, BS, Lindstrasse 51, 8400 Winterthur, Switzerland (e-mail: micha-sch@gmx.ch). interphalangeal [PIP] joint flexed, distal interphalangeal [DIP] joint hyperextended). ${ }^{8}$ In addition, friction between tendon and pulley, which increases with PIP joint flexion, can make the pulley more susceptible to injury when this holding technique is used. ${ }^{9,10}$ Finally,

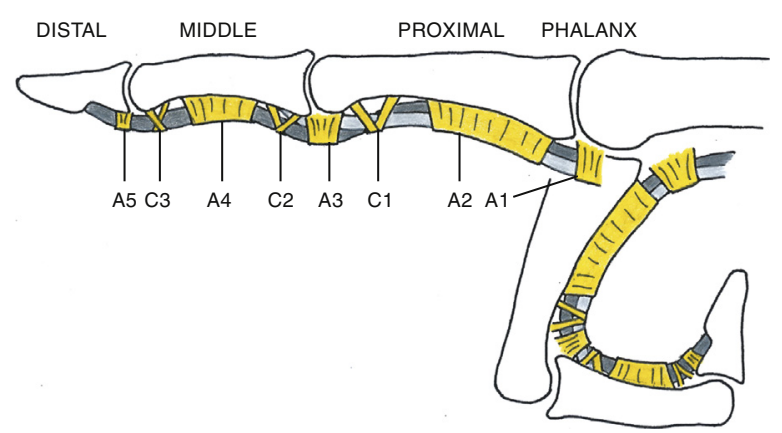

Figure 1. The finger flexor tendons glide in a sheath reinforced by annular (A1-A5) and cruciform (C1-C3) pulleys. The tendons are kept close to the phalanges also during finger flexion. 
peak loads on the pulley system, such as those occurring during dynamic climbing moves or after slipping off a foothold, often trigger a rupture. ${ }^{4,5,11-18}$

The loss of anatomic pulley integrity results in a palpable protrusion caused by the dehiscence of flexor tendons and phalanges, especially in forced finger flexion, ${ }^{5,11-14,16-24}$ and is equivalent to functional deficiency; the diminished tendon amplitude causes a deficit in both strength ${ }^{25}$ and range of motion (ROM) of the affected finger. Depending on the number of pulleys ruptured, the increased tendon-phalanx distance (TPD) can be visible as so-called bowstringing. ${ }^{4,17,26}$ Suspected pulley rupture can be reliably confirmed by ultrasound measurement of TPD, ${ }^{20,23}$ which is recommended for routine diagnosis. ${ }^{4,21,23}$

Conservative treatment of pulley ruptures involves first immobilization, then a gradual increase in the intensity of finger exercise, including easy climbing, always under pulley protection. ${ }^{4,12-15,17}$ This is conventionally done with a simple inelastic tape or with a thermoplastic ring. ${ }^{4,5,13-17}$ Good clinical results, ${ }^{4,11,13,24,25}$ albeit with TPD remaining increased, ${ }^{4,11,14,17,25}$ have been reported. Surgical reconstruction, recommended as second-line treatment, ${ }^{12,13,24,25,27}$ has been noted to reduce TPD $^{6,14,19,27}$ but involves risks associated with invasive procedures.

We developed a novel device, the pulley-protection splint (PPS), which we have used for conservative treatment of pulley ruptures since 2007. In contrast with conventional taping, the splint's shape allows firm fixation on the finger with inelastic tape, but without compression of blood vessels or nerves (Figure 2). The flexor tendons are thus forced back into a nearly anatomic position, and the pulley can heal at a functionally effective length, close to its original state, which is equivalent to TPD reduction.

In the present case series, we evaluated the effectiveness of conservative treatment of pulley rupture with the PPS by quantifying TPD reduction and investigating functional and sport-specific outcomes.

\section{Methods}

The present study is a systematic retrospective analysis of pulley ruptures seen in our clinic during a period of several years. Concerning diagnosis, treatment, and follow-up, the procedure subsequently described represents our clinic's standard algorithm for pulley ruptures receiving conservative treatment and was not designed for or influenced by the study.

Subjects eligible for the present study were rock climbers older than 18 years who experienced closed complete pulley rupture a minimum of 6 months before the survey and were treated conservatively with a PPS (start of therapy between December 2007 and May 2013).

All patients provided written informed consent to participate in the study. The responsible ethics committee approved the study.

\section{DIAGNOSIS AND TREATMENT}

Patients were clinically examined and diagnosed in our clinic. Mean interval between pulley rupture and first consultation was 18.0 days (range, 1-83 days). Ultrasound was used to quantify the amount of bowstringing over the disrupted pulley. Tendon-phalanx distance was

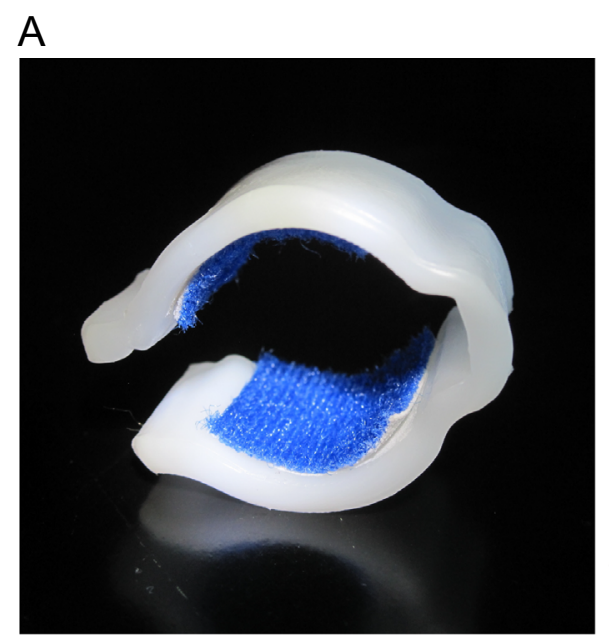

B

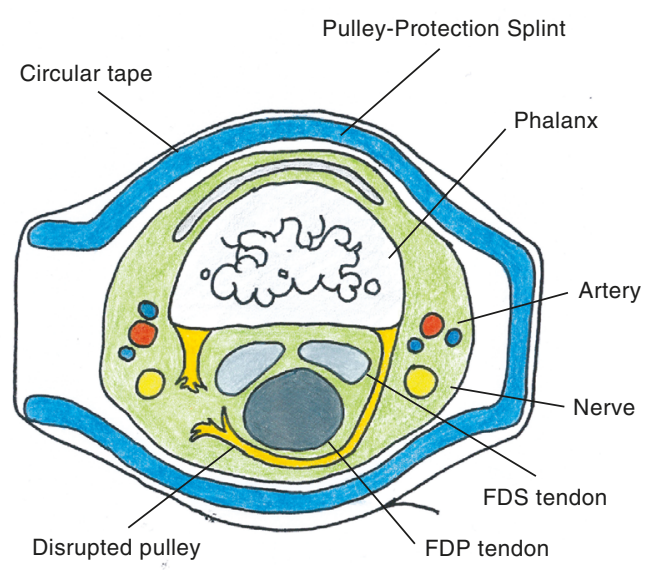

Figure 2. A, Pulley-protection splint with padding on the contact zones to provide a comfortable fit. B, The splint's lateral convexities prevent compression of blood vessels and nerves running along both sides of the finger. FDP, flexor digitorum profundus tendon; FDS, flexor digitorum superficialis tendon. 


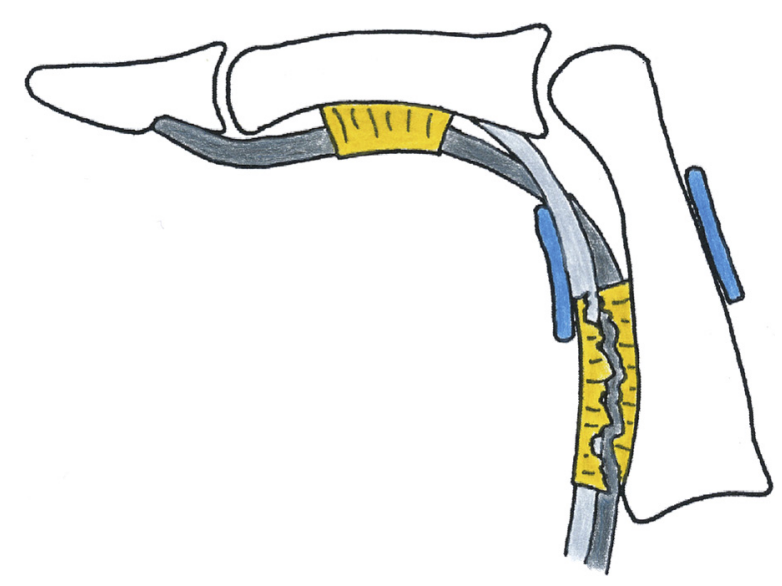

Figure 3. The pulley-protection splint forces the flexor tendons back into their usual position close to the phalanges. The most effective bowstringing reduction is achieved when the splint is placed right next to the proximal interphalangeal joint, here in case of an A2 pulley rupture.

measured in the middle of the corresponding phalanx in the longitudinal plane with the palm of the hand facing upward and the finger flexed against resistance (DIP joint at $10^{\circ}$, PIP joint at $40^{\circ}$, metacarpophalangeal joint extended $\left.^{20,22,23}\right)$. The ultrasound device used was a Philips iU22 (Philips Healthcare, Inc, Bothell, WA) with a 17.5-MHz linear transducer. Scaled screen shots of the examinations were taken and retrospectively analyzed.

All climbers included in the study were treated conservatively with a custom PPS, which they wore continuously until the first follow-up, at 2 months. To achieve the most effective reduction of bowstringing, the PPS was placed close to the PIP joint rather than over the pulley itself (Figure 3). ${ }^{28}$ The PPS is made of 3.2-mm thermoplastic splinting material (Rolyan Aquaplast Original, solid; Patterson Medical, Warrenville, IL); for A4 pulleys also 2.4-mm Aquaplast can be used. Using a conical wooden bar 8 to $12 \mathrm{~mm}$ in diameter as a template, the warmed Aquaplast is shaped into a splint corresponding to finger size. Two aluminum bands

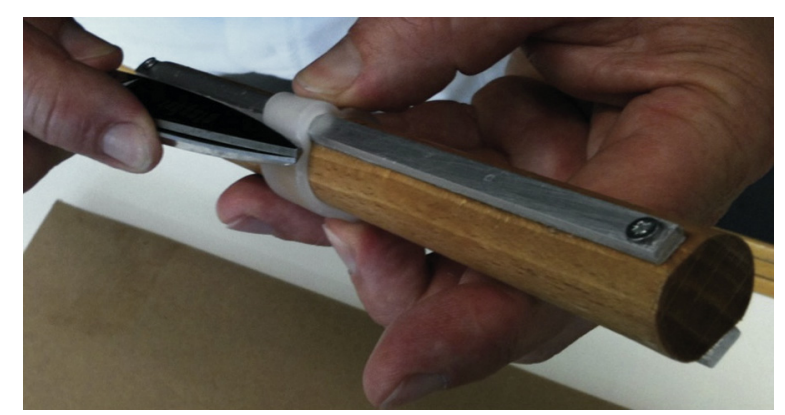

Figure 4. Shaping a customized pulley-protection splint using a template.

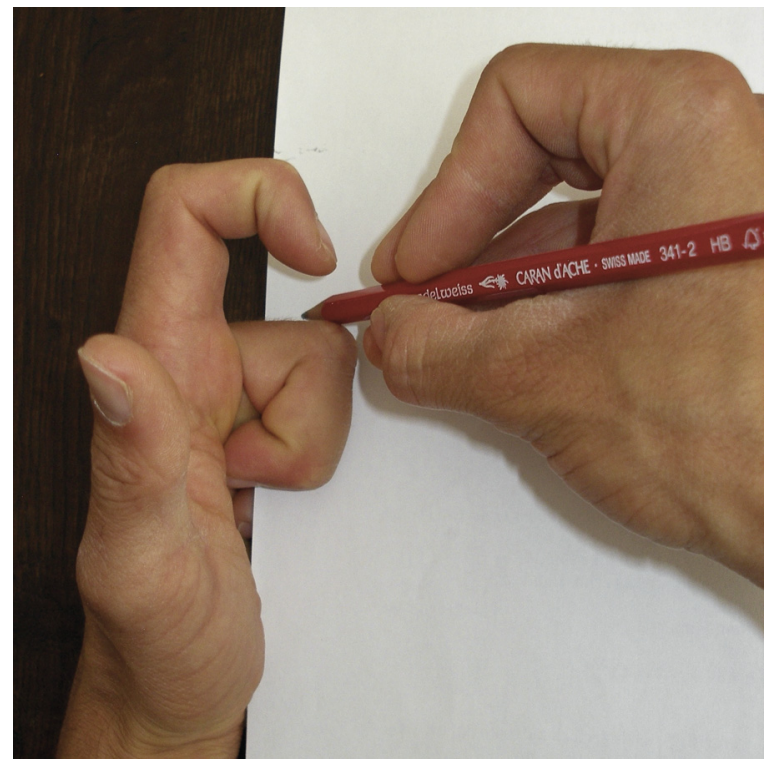

Figure 5. Explanatory picture from the questionnaire showing how to record the outline of the back of the finger on a piece of paper for later analysis of range of motion, here for the middle finger in maximal flexion.

attached to opposite sides of the bar create bilateral convexities in the splint (Figure 4).

Easy climbing using large holds on faces not angled beyond vertical was allowed 3 to 4 weeks after injury. Gradual weaning off the PPS started after 2 months, using a tape instead. The patients could finally move on to normal climbing exercise after 3 to 5 months, depending on the healing progress.

\section{FOLLOW-UP}

A follow-up ultrasound monitoring under stress was performed as described previously around 2 months after diagnosis. Again, scaled screen shots of the examinations were taken and retrospectively analyzed. On study inclusion, the participants were mailed a questionnaire about the circumstances at the event of injury, and functional and sport-specific outcomes. The questionnaire included multiple-choice questions as well as instructions for self-measurement of finger ROM and finger strength detailed enough to allow the participants to perform the measurements on their own without further support.

Finger ROM measurements were performed for the treated and contralateral fingers 3 times in maximal flexion and extension. A thick piece of paper was placed between the fingers so that the finger of interest was lying directly on the paper. An outline of the finger was then recorded on the paper by tracing the back of the 
Table 1. Criteria for assessment of finger range of motion

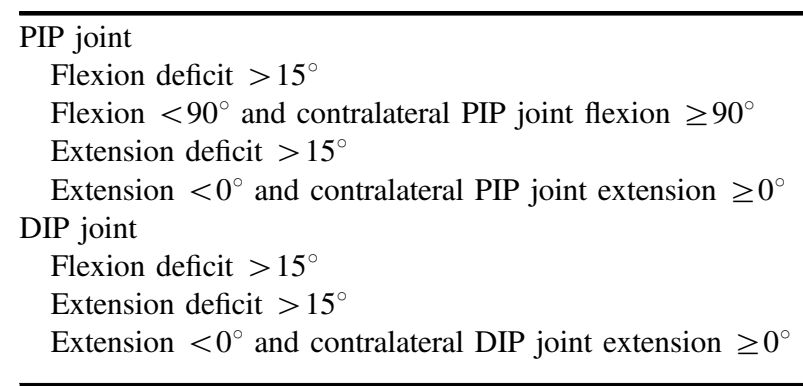

DIP, distal interphalangeal; PIP, proximal interphalangeal.

finger with a pen (Figure 5). The position of each interphalangeal joint was marked with a short dash. From the outlines obtained, we were able to determine the ROMs of the interphalangeal joints. The best angles obtained for each joint were used for analysis. The values of the treated finger were compared with those of the contralateral finger. If at least 1 of the 7 criteria (Table 1) was fulfilled, the ROM of the treated finger was judged to be restricted.

Finger strength measurements were carried out after proper warm-up. As much body weight as possible had to be released from a bathroom scale by maximally pulling on an overhead edge (1.5-2 cm deep, eg, a doorframe) with the distal phalanges of the fingers. The reading was recorded as soon as it showed a stable value. $^{25,29}$ The procedure was performed one-handed for both hands with the index, middle, and ring fingers combined in both crimp and slope grips (PIP joint extended, DIP joint flexed), as well as for the treated and contralateral fingers isolated using the slope grip (no crimping because of the risk of reinjury). Because there is no apparent difference in finger strength between the right and left hands in trained climbers, ${ }^{10,13,25,30-32}$ the weight released from the scale by the treated side can be expressed as a percentage of the value of the uninjured side, allowing interindividual comparison despite the use of edges of different sizes. The strength of the treated side was judged to be decreased if at least 1 of the 3 values obtained was less than $80 \%$ that of the uninjured side.

To assess climbing level, the French grading scale was converted to a metric scale based on Schöffl's method. ${ }^{4}$ The scale ranges from 1.00 to 11.75 currently. The hardest climbing route accomplished in the 2 years before pulley rupture was considered a patient's initial climbing level. With regard to sport-specific outcome, the participants were judged to have regained their previous climbing level if the grade of the hardest route accomplished since pulley rupture was no more than
0.25 below their initial climbing level on the metric scale in either on-sight or redpoint style.

Some questionnaires were returned with missing answers. Measurement results or subjective answers possibly influenced by later injuries or current pain were not considered. For these reasons, the total number of cases in the results section varies for different findings.

\section{STATISTICAL ANALYSIS}

We performed 1-sample (strength) and paired (TPD, ROM except PIP joint extension) $t$ tests after verifying normal distribution using the Kolmogorov-Smirnov test. In cases of data not normally distributed (PIP joint extension), we performed the Wilcoxon signed-rank test. All tests were 2-tailed. A probability value less than .05 was considered significant. SPSS Statistics 21 (IBM Corp, Armonk, NY) and Excel 2008 (Microsoft Corp, Redmond, WA) were used for the statistical analysis.

\section{Results}

Of the 48 patients meeting the defined inclusion criteria for this study, 1 could not be contacted and 2 failed to return the survey documents. Ultimately, 47 complete pulley ruptures in 45 rock climbers were included in this study. The 2 climbers who experienced 2 pulley ruptures, 1 on each of 2 fingers, were considered 2 cases each. Detailed information is summarized in Tables 2 through 4. Two A2 pulley ruptures were combined with an A3 pulley rupture, of which 1 had an additional rupture of the flexor digitorum superficialis tendon of the same finger that was treated conservatively because of good ROM and the difficulty of reconstruction.

Follow-up ultrasound examination was performed in 39 patients a mean 66.9 days (range, 42-104 days) after the first consultation. Therapy with the PPS significantly reduced TPD after both A2 $(P<.001)$ and A4 $(P<$ $.001)$ pulley rupture (Table 5). Tendon-phalanx distance

Table 2. Population details $(n=47)$

\begin{tabular}{ll}
\hline Sex & \\
Male & 40 \\
Female & 7 \\
Age at event of injury (years) & $33.4(21.8-56.2)$ \\
Climbing practice (years) & $11.0(1-30)$ \\
Initial climbing level & \\
$\quad$ On-sight (metric) & \\
Redpoint (metric) & $7.87(5.50-9.50)$ \\
\end{tabular}

Data (except sex) presented as mean (range).

* Unknown in 3 patients.

${ }^{\dagger}$ Unknown in 4 patients. 
Table 3. Circumstances at the event of injury $(n=47)$

\begin{tabular}{lr}
\hline Warm-up $^{*}$ & 25 \\
Proper & 15 \\
Bad & 3 \\
No warm-up & \\
Hold used & 25 \\
Narrow edge & 3 \\
$\quad$ Undercling edge & 8 \\
Finger pocket & 2 \\
$\quad$ Undercling pocket & 4 \\
Pinch & 4 \\
Undercling, not further specified & 4 \\
Other & \\
Finger position & 35 \\
Crimp grip & 6 \\
Slope grip & \\
Injury trigger & 30 \\
Peak load & 19 \\
$\quad$ Dynamic move & 5 \\
$\quad$ Slipping off a foothold & 15 \\
Static stress & \\
\hline
\end{tabular}

* Unknown in 4 patients.

${ }^{\dagger}$ Unknown in 2 patients.

* Unknown in 6 patients.

was reduced in all 39 fingers (Figure 6). Figure 7 shows the ultrasound findings before and after treatment in 1 patient.

Forty-four climbers completed the questionnaire a mean 34.1 months (range, 8.6-74.5 months) after pulley rupture. According to the measurements, 7 of 42 fingers had restricted ROM, whereas 6 of 42 patients subjectively described the finger's pattern of movement as slightly disturbed. There was no significant difference between sides in any finger joint (Table 6). Measurements of finger strength revealed loss of strength in 4 of 22 cases; 8 of 43 climbers reported minor loss of strength in the treated finger. Compared

Table 4. Injury distribution $(n=47)$

\begin{tabular}{lc}
\hline Injury location & $n$ \\
\hline A2 pulley & 28 \\
A4 pulley & 19 \\
Index finger & 1 \\
Middle finger & 17 \\
Ring finger & 29 \\
Right side & 21 \\
Left side & 26 \\
Dominant side & 21 \\
Nondominant side & \\
& \\
\hline
\end{tabular}

\footnotetext{
${ }^{*}$ Handedness unknown in 1 patient.
}

Table 5. Before and after treatment tendon-phalanx distance

\begin{tabular}{llll}
\hline & \multicolumn{2}{c}{$T P D(\mathrm{~mm})$} & \\
\cline { 2 - 3 } Variable & Diagnosis & Follow-up & P value \\
\hline A2 pulley $(\mathrm{n}=24)$ & $4.4( \pm 1.0)$ & $2.3( \pm 0.6)$ & $<.001$ \\
A4 pulley $(\mathrm{n}=15)$ & $2.9( \pm 0.7)$ & $2.1( \pm 0.5)$ & $<.001$ \\
\hline
\end{tabular}

Data are presented as mean $( \pm \mathrm{SD})$.

$\mathrm{TPD}$, tendon-phalanx distance.

with the contralateral side, strength was significantly less than $100 \%$ when using the crimp grip, but did not differ significantly when using the slope grip (Table 7).

Thirty-eight of 43 participants regained their previous climbing level a mean 8.8 months (range, 2-36 months) after pulley rupture. Of the 5 who did not, 3 reported climbing less than before the injury (all for reasons not related to the pulley injury) and 2 climbed as much as before. Forty of 43 climbers stated that, when climbing, they could expose the treated finger to maximal loads a mean 7.3 months (range, 2-18 months) after pulley rupture, whereas in 3 cases loading capability remained reduced. Two of 43 participants were still bothered by occasional pain during or after climbing; the others reported no $(\mathrm{n}=31)$ or hardly any $(\mathrm{n}=10)$ pain. Ten of 43 climbers taped the finger for more than 12 months after pulley rupture, of whom 7 considered the taping to provide mainly mental support and 3 considered it helpful, but none considered it indispensable. Both patients who experienced pulley rupture less than 12 months earlier had stopped taping at the time of the survey.

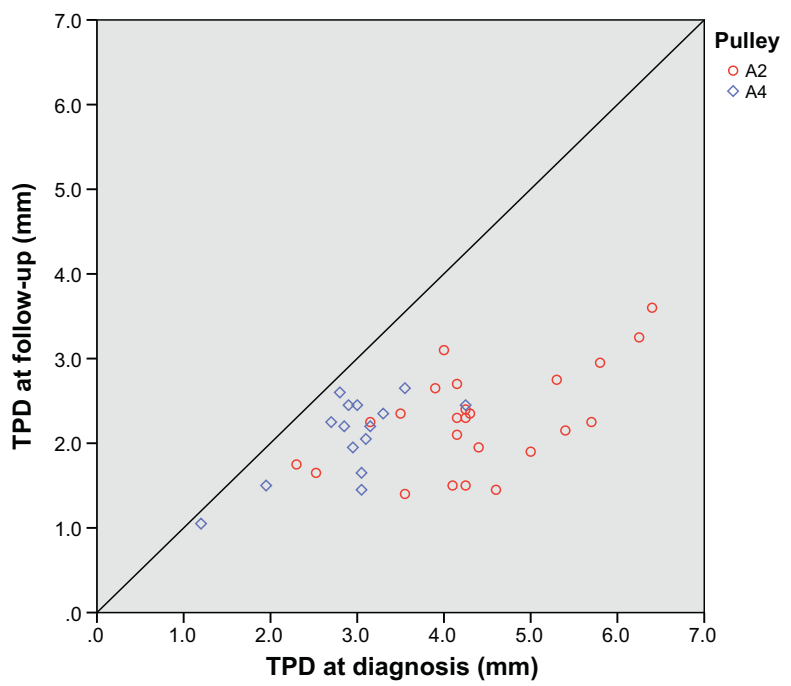

Figure 6. Effect of treatment with the pulley-protection splint on tendon-phalanx distance (TPD). Tendon-phalanx distance was reduced in all 39 climbers who were followed up with ultrasound. 
With regard to limitations in everyday life (pain or reduced finger ROM or dexterity), of 43 participants, 1 reported reduced finger dexterity when playing the guitar, 39 assessed the result of treatment as very good, 4 assessed it as good, and all 43 would undergo the same treatment again. To our knowledge, secondary surgery was not necessary in any patient.

The patient with the additional flexor digitorum superficialis tendon rupture first improved well (difficult climbing without pain after 3 months), but experienced a secondary trauma 6 months after the first injury causing pain until today. Answers of the questionnaire influenced thereby were not considered for evaluation.

\section{Discussion}

Pulley rupture, a very common sport climbing injury, is accompanied by increased TPD measured with ultrasound. Conventional conservative treatment leads to good results, although TPD remains increased. Surgery has been noted to reduce TPD but involves various treatment-related risks. The present study analyzed the impact of conservative treatment with the PPS on TPD and investigated this method's functional and sportspecific outcomes.

\section{TENDON-PHALANX DISTANCE}

Treatment of pulley ruptures with the PPS significantly reduced TPD in all affected fingers. This can be attributed to the splint's particular shape, which features collateral bulges. This allows strong compression of the finger while preventing neurologic impairment or obstruction of blood circulation (Figure 2). Because the flexor tendons are kept close to the phalanx during the reparative process, the pulley can heal in a length closer to normal than without the PPS. The smallest possible TPD attainable with the PPS is approximately $2 \mathrm{~mm}$ in

Table 6. Range of motion $(n=42)$

\begin{tabular}{lccc}
\hline Variable & Affected side & Contralateral side & $\mathrm{P}$ value \\
\hline Flexion $\left(^{\circ}\right)$ & & & \\
PIP joint & $105( \pm 9)$ & $107( \pm 9)$ & .23 \\
DIP joint & $67( \pm 16)$ & $69( \pm 15)$ & .28 \\
Extension $\left(^{\circ}\right)$ & & & \\
PIP joint & $1( \pm 9)$ & $1( \pm 8)$ & .44 \\
DIP joint & $-7( \pm 7)$ & $-6( \pm 8)$ & .28 \\
Global ROM $\left(^{\circ}\right)^{*}$ & $179( \pm 25)$ & $181( \pm 24)$ & .45 \\
\hline
\end{tabular}

Data are presented as mean $( \pm \mathrm{SD})$.

DIP, distal interphalangeal; PIP, proximal interphalangeal; ROM, range of motion.

* Not assessable in 3 patients.
Table 7. Strength of affected side $(\mathrm{n}=22)$

\begin{tabular}{lcc}
\hline Variable & \% Contralateral side & $\mathrm{P}$ value \\
\hline I, M, R combined & & \\
$\quad$ Slope grip & $97( \pm 11)$ & .22 \\
$\quad$ Crimp grip & $96( \pm 8.7)$ & .030 \\
Affected finger isolated & & \\
$\quad$ Slope grip & $96( \pm 15)$ & .24 \\
\hline
\end{tabular}

Data are presented as mean $( \pm \mathrm{SD})$.

$\mathrm{I}$, index finger; $\mathrm{M}$, middle finger; $\mathrm{R}$, ring finger.

* Test value $=100 \%$.

${ }^{\dagger}$ No value in 1 patient.

active forced flexion (Figure 6, Table 5). Physiologic TPD in active forced flexion is about $1 \mathrm{~mm}{ }^{20}$

Tendon-phalanx distance has been reported to be reduced only by surgery, ${ }^{6,14,19,27}$ but observed to stay reasonably stable when treated by conventional conservative means $s^{4,11,14,17,25}$ because pressure applied to the finger is limited.

\section{FUNCTIONAL AND SPORT-SPECIFIC OUTCOMES}

We observed unrestricted ROM in more than 4 of 5 affected fingers and no difference between sides. Similarly, Schöffl et $\mathrm{al}^{25}$ described full ROM in 16 of 27 fingers after conventional conservative treatment, but a remaining extension deficit of $5^{\circ}$ to $10^{\circ}$ in 10 PIP joints and a flexion deficit of $20^{\circ}$ in 1 PIP joint. Bouyer et $\mathrm{al}^{27}$ found postoperative global ROM of the operated finger to be $97 \%$ that of the opposite side and a fixed flexion deformity of $12^{\circ}$ to $32^{\circ}$ in 6 of 24 PIP joints; in yet another study, Arora et $\mathrm{al}^{33}$ found active movement of the different joints in 23 fingers that were operated on to

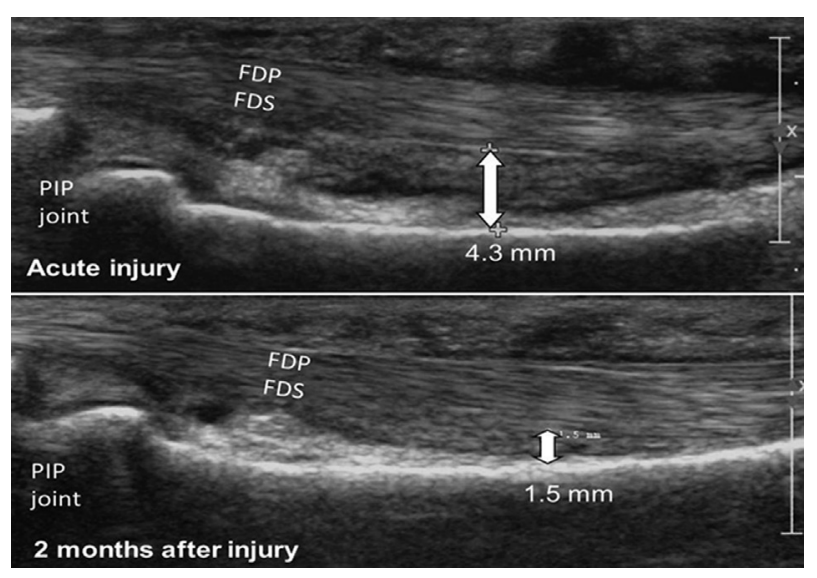

Figure 7. Tendon-phalanx distance in an A2 pulley rupture before (top) and after (bottom) treatment with a pulley-protection splint. FDP, flexor digitorum profundus tendon; FDS, flexor digitorum superficialis tendon; PIP, proximal interphalangeal. 
be almost unrestricted. In our study, the strength of the treated side was normal in more than 4 of 5 climbers and not significantly different from the uninjured side when using the slope grip. The difference in strength when using the crimp grip, despite mean strength being $96 \%$ that of the contralateral side, could be the result of the small number of cases. Also, no difference in finger strength was observed between sides after conventional conservative or surgical treatment. ${ }^{25,27,33}$ Most climbers in the present study regained their previous climbing level within less than 12 months, which is consistent with reported results of conventional conservative and surgical treatments. ${ }^{25,27,33}$ Almost three-quarters of our study participants reported being completely free of pain during or after climbing. In the survey of Schöffl et al, ${ }^{25}$ 8 of 27 patients treated with a conventional conservative method reported having occasional problems when climbing, whereas Bouyer et $\mathrm{al}^{27}$ reported that $64 \%$ of the operated climbers were free of pain. Residual restrictions in everyday life are exceptional regardless of the treatment modality, as seen in the present and previous studies. ${ }^{25,33}$ In addition, satisfaction among the patients was very high in general, both in the present study and in studies reporting surgical outcomes. ${ }^{27,33}$

The findings of various other studies ${ }^{4,11,13,24}$ support the possibility of regaining finger functionality and preinjury climbing performance without surgical repair. The notion that reconstruction is the only way to return to normal finger function after complete A2 or A4 pulley rupture $^{15,16,18}$ may be inaccurate, inasmuch as in the present study a lack of full functional recovery after conservative treatment appeared to be restricted to particular cases, as observed elsewhere. ${ }^{34}$

\section{IMPLICATIONS FOR TREATMENT SELECTION}

Functional and sport-specific outcomes of PPS treatment have been shown to be quite similar to those of conventional conservative ${ }^{25}$ and surgical treatments. ${ }^{27,33}$ In addition, outcomes of conservative and operative treatment groups within the same study have been reported to be equal. ${ }^{14,27}$ The present study confirms previous findings suggesting that surgery after single pulley rupture, with its associated risks of neurovascular impairment, infection, scar formation, adhesions, and graft failure or pain at the donor site, should be performed only in case of failure of nonoperative treatment. ${ }^{12,13,24,25,27}$

We recommend the use of the PPS as a conservative treatment because of its positive effect on TPD, in contrast with conventional methods. However, we cannot deduce from our data whether and to what extent a small TPD is responsible for good functional and sportspecific outcomes. A small number of our participants experienced an unsatisfactory outcome, which prevents a valid comparison with the superior subgroup regarding posttreatment TPD. Still, a small TPD can be assumed beneficial to the climber, as it is conducive to complete recovery of finger ROM and finger strength. Protrusion of the flexor tendons can cause discomfort on large holds or be cosmetically disturbing.

\section{LIMITATIONS}

This study featured self-measurements of finger ROM and finger strength instead of time-consuming investigations at our clinic, which increased the number of patients willing to participate. A drawback was that execution of the measurements could not be supervised. Reliability of the used method for finger ROM measurement has not been validated systematically in advance. As a case series, this study does not include control groups, who received conventional conservative treatment or surgical repair. Therapy outcome of the PPS was compared with the results of other studies instead.

\section{Conclusions}

The PPS is an effective conservative treatment modality for pulley ruptures, which reduces TPD and enables the patient to regain previous finger function in terms of active ROM, strength, and performance during everyday life as well as while climbing.

\section{References}

1. Doyle JR, Blythe W. The finger tendon flexor sheath and pulleys: anatomy and reconstruction. In: AAOS Symposium on Tendon Surgery in the Hand. St. Louis, MO: CV Mosby Co; 1975:81-87.

2. Peterson WW, Manske PR, Bollinger BA, Lesker PA, McCarthy JA. Effect of pulley excision on flexor tendon biomechanics. J Orthop Res. 1986;4:96-101.

3. Lin GT, Amadio PC, An KN, Cooney WP. Functional anatomy of the human digital flexor pulley system. $J$ Hand Surg Am. 1989;14:949-956.

4. Schöffl V, Hochholzer T, Winkelmann HP, Strecker W. Pulley injuries in rock climbers. Wilderness Environ Med. 2003;14:94-100.

5. Bollen SR, Gunson CK. Hand injuries in competition climbers. Br J Sports Med. 1990;24:16-18.

6. Gabl M, Reinhart C, Lutz M, Bodner G, Angermann P, Pechlaner S. The use of a graft from the second extensor compartment to reconstruct the A2 flexor pulley in the long finger. J Hand Surg (Br). 2000;25:98-101.

7. Schöffl VR, Jüngert J. Closed flexor pulley injuries in nonclimbing activities. $J$ Hand Surg Am. 2006;31: 806-810. 
8. Hume EL, Hutchinson DT, Jaeger SA, Hunter JM. Biomechanics of pulley reconstruction. J Hand Surg Am. 1991;16:722-730.

9. Zhao CF, Amadio PC, Berglund L, An KN. The A3 pulley. J Hand Surg Am. 2000;25:270-276.

10. Schweizer A, Frank O, Ochsner PE, Jacob HAC. Friction between human finger flexor tendons and pulleys at high loads. J Biomech. 2003;36:63-71.

11. Bollen SR. Injury to the A2 pulley in rock climbers. J Hand Surg (Br). 1990;15:268-270.

12. Gabl M, Lener M, Pechlaner S, Judmaier W. Isolated injuries of the pulley of the finger flexor tendon sheath injuries in extreme climbing sports [in German]. Sportverletz Sportschaden. 1992;6:119-122.

13. Gabl M, Lener M, Pechlaner S, Lutz M, Rudisch A. Rupture or stress injury of the flexor tendon pulleys? Early diagnosis with MRI [in German]. Handchir Mikrochir Plast Chir. 1996;28:317-312

14. Gabl M, Rangger C, Lutz M, Fink C, Rudisch A, Pechlaner S. Disruption of the finger flexor pulley system in elite rock climbers. Am J Sports Med. 1998;26:651-655.

15. Moutet F, Guinard D, Gerard P, Mugnier C. Subcutaneous rupture of long finger flexor pulleys in rock climbers. 12 case reports [in French]. Ann Chir Main Memb Super. 1993;12:182-188.

16. Moutet F. Flexor tendon pulley system: anatomy, pathology, treatment [in French]. Chir Main. 2003;22:1-12.

17. Schöffl V, Hochholzer T, Winkelmann HP, Roloff I, Strecker W. Pulley injuries in sport climbers [in German]. Handchir Mikrochir Plast Chir. 2004;36:224-230.

18. Voulliaume D, Forli A, Parzy O, Moutet F. Surgical repair of flexor tendon pulley rupture in high level rock climbing [in French]. Chir Main. 2004;23:243-248.

19. Le Viet D, Rousselin B, Roulot E, Lantieri L, Godefroy D. Diagnosis of digital pulley rupture by computed tomography. J Hand Surg Am. 1996;21:245-248.

20. Bodner G, Rudisch A, Gabl M, Judmaier W, Springer P, Klauser A. Diagnosis of digital flexor tendon annular pulley disruption: comparison of high frequency ultrasound and MRI. Ultraschall Med. 1999;20:131-136.

21. Martinoli C, Bianchi S, Nebiolo M, Derchi LE, Garcia JF. Sonographic evaluation of digital annular pulley tears. Skeletal Radiol. 2000;29:387-391.

22. Klauser A, Frauscher F, Bodner G, et al. Value of highresolution ultrasound in the evaluation of finger injuries in extreme sport climbers [in German]. Ultraschall Med. 2000;21:73-78.
23. Klauser A, Frauscher F, Bodner G, et al. Finger pulley injuries in extreme rock climbers: depiction with dynamic US. Radiology. 2002;222:755-761.

24. Schöffl V, Hochholzer T, Winkelmann HP, Strecker W. Therapy of injuries of the pulley system in sport climbers [in German]. Handchir Mikrochir Plast Chir. 2004; 36:231-236.

25. Schöffl VR, Einwag F, Strecker W, Schöffl I. Strength measurement and clinical outcome after pulley ruptures in climbers. Med Sci Sports Exerc. 2006;38: 637-643.

26. Marco RA, Sharkey NA, Smith TS, Zissimos AG. Pathomechanics of closed rupture of the flexor tendon pulleys in rock climbers. $J$ Bone Joint Surg Am. 1998;80:1012-1019.

27. Bouyer M, Semere A, Mesquida V, Forli A, Corcella D, Moutet F. Long-term results of surgical reconstruction of subcutaneous pulley ruptures in high-level climbers according to Lister technique: about 38 patients [in French]. Chir Main. 2014;33:417.

28. Schweizer A. Biomechanical effectiveness of taping the A2 pulley in rock climbers. $J$ Hand Surg (Br). 2000;25:102-107.

29. Köstermeyer G, Weineck J. Necessity of individual finger training of finger flexor muscles to improve performance in sport climbing. Comparison of power development at one- and four-fingered maximum contraction [in German]. Dtsch Z Sportmed. 1995;46:356-362.

30. Grant S, Hynes V, Whittaker A, Aitchison T. Anthropometric, strength, endurance and flexibility characteristics of elite and recreational climbers. J Sports Sci. 1996;14: 301-309.

31. Grant S, Hasler T, Davies C, Aitchison TC, Wilson J, Whittaker A. A comparison of the anthropometric, strength, endurance and flexibility characteristics of female elite and recreational climbers and non-climbers. $J$ Sports Sci. 2001;19:499-505.

32. Watts PB, Jensen RL. Reliability of peak forces during a finger curl motion common in rock climbing. Meas Phys Educ Exerc Sci. 2003;7:263-267.

33. Arora R, Fritz D, Zimmermann R, et al. Reconstruction of the digital flexor pulley system: a retrospective comparison of two methods of treatment. J Hand Surg Eur Vol. 2007;32:60-66.

34. Schöffl I, Baier T, Schöffl V. Flap irritation phenomenon (FLIP): etiology of chronic tenosynovitis after finger pulley rupture. J Appl Biomech. 2011;27:291-296. 